materials such as matches and naked lights caused 131 fatal fires, 25 per cent of the fatal fires from known causes. Electrical appliances and fires in grates each cause 19 per cent, and although children with fire caused only 5 per cent, this proportion is increasing. The number of incidents in which more than one person has died has been increasing over the past six years, and stands at 78 for 1966. Fires in buildings were more frequent in winter than in summer, while the

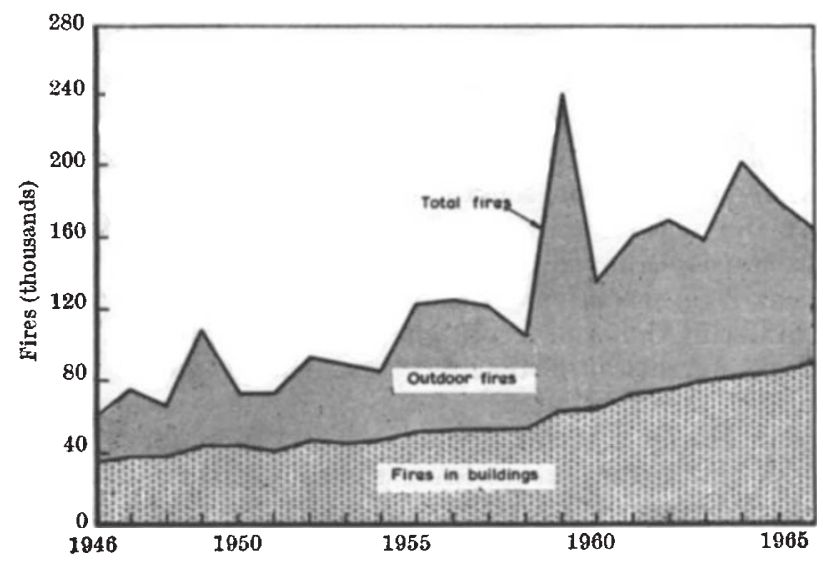

Annual incidence of fires in the United Kingdom (from United Kingdom Fire Statistics for 1966).

reverse was true for fires not in buildings. The largest fire loss for a single month was estimated at more than $£ 10$ million, and the smallest at about $£ 4$ million. A computer was used for the first time to produce the 1966 tables and it is hoped that in future results will be produced more quickly.

\section{Design for a Fusion Reactor}

THE major problem of using nuclear fusion to produce power remains that of stabilizing a high temperature plasma for long enough for the reactions to produce a net gain of power. Although this has yet to be achieved, some rather speculative studies have been made of the engineering characteristics of fusion reactors. $\mathrm{Mr} \mathrm{R}$. Carruthers, Dr P. A. Davenport and Dr J. T. D. Mitchell of the Culham Laboratory of the United Kingdom Atomic Energy Authority have written the most recent of these, called The Economic Generation of Power from Thermonuclear Fusion (HMSO, 4s. 6d.).

All, or almost all, designs for fusion reactors use magnetic fields as a means of keeping the very hot gases together. The authors of this report do the same, and suggest that the best geometry for the reactor is toroidal-doughnut shaped. The plasma, at a temperature of $7 \cdot 10^{8} \mathrm{~K}$, is contained in what amounts to a cylinder with the open ends joined to form a closed loop. The fuel used is a 50/50 mixture of deuterium and tritium. To get the reactor started, both fuels would be injected into the reactor, but once it was operating it would generate it own tritium in a blanket of molten salt surrounding the plasma. The blanket, containing lithium salts, would generate tritium by the $\mathrm{Li}(\mathrm{n}, \mathrm{t})$ reaction, and would also act as a means of extracting the useful heat from the reactor. Thus the blanket would be circulated through salt pumps and heat extractors, and the lithium replenished. In this sense, the real fuels for the reactor would be deuterium and lithium.

The reactor chosen for the study is one of 5,000 MW (thermal), or 1,250 MW (electrical). The authors estimate that the capital cost of such a system would be between $£ 68.5$ and $£ 74$ per $\mathrm{kW}$, the greater part of this ( $£ 29$ per $\mathrm{kW}$ ) being spent on conventional equipment, which includes the salt recirculating pumps, and the necessary electrical equipment. The second most expensive item is the superconducting magnet which would be used to keep the plasma in the right place; the reactor vessel and "blanket" would be reasonably cheap, only $£ 4$ per $\mathrm{kW}$. On the basis of a 25 year life at 80 per cent load factor, and interest rates of 8 per cent, the generating costs of such a system would be $0 \cdot 23$ to 0.25 pence per $\mathrm{kWh}$, of which the vast majority is attributable to the capital costs of the station. Fuel charges would be only 0.004 pence per $\mathrm{kWh}$, and operation and maintenance 0.017 pence per $\mathrm{kWh}$.

But the authors concede that there are a number of problems outstanding before this type of reactor can be built. The most obvious one, of course, is that of plasma containment, but there are others; the properties of the vacuum wall, for example, would need to be quite unusual. Fuel injection and exhaust extraction would also be a problem. It would even be quite hard to get the reactor started. For all that, the report is striking evidence of the continued optimism of those involved in fusion research.

\section{Crystal Growing}

ThE Science Research Council has awarded a grant of $£ 14,505$ to Dr J. N. Sherwood, of the University of Strathclyde, Glasgow, to set up facilities for the growth of organic molecular erystals. Molecular solids are attracting a great deal of attention at present because of their uses in solid state devices. In particular, the electro-optical properties of many organic crystals suggest applications in radiation detectors-a familiar example is the use of certain aromatic phosphors in scintillation counters.

The electrical, optical and mechanical properties of these solids frequently depend on the structure of the material as well as its chemical composition. This is why there is a demand for high quality single crystals of organic substances.

Dr Sherwood will use the SRC grant to provide a crystal growing service for the universities and industry. This seems to be a desirable step. Crystal growing can require specialized equipment, and is frequently timeconsuming. Because many research workers need only a few samples of the crystals they are studying, it is logical to have a laboratory with the facilities and the skill to provide the service.

\section{Effects of Malnutrition}

ONCE again the need to produce more food to keep up with trends in increasing population and changing social habits has been stressed. This time it is the joint FAO/WHO Expert Committee on Nutrition in its seventh report (published with two alternative covers as $W H O$ Tech. Rep. Series No. 377, and FAO Nutrition Meetings Rep. Series No. 42).

The report reviews the state of knowledge in relation to nutritional requirements, and includes a discussion 